\title{
Laugier-Hunziker syndrome: a rare case report and review of the literature
}

\section{Laugier-Hunziker sendromu: Nadir bir olgu sunumu ve literatürün gözden geçirilmesi}

\author{
Hande Ermis ${ }^{1}$ \\ ${ }^{1}$ Dept. of Dermatology and Veneorology, Karadeniz Technical University Faculty of Medicine, Trabzon, Turkey
}

\begin{abstract}
Laugier-Hunziker syndrome is a rare, hereditary pigmentary disorder characterized by mucocutaneous lentiginous lesions and melanonychia. The condition is regarded as benign since underlying malignancies or systemic disorders were not reported. Since various malignancy syndromes including Peutz-Jeghers and Cronkhite-Canada syndrome and systemic cause of hyperpigmentation such as Addison disease and drugs are presented with similar mucocutaneous findings, it is of paramount importance to assess the patients to exclude aforementioned conditions.
\end{abstract}

Key words: Laugier-Hunziker syndrome, mucocutaneous hyperpigmentation, melanonychia

\section{$\ddot{\mathrm{O} z}$}

Laugier-Hunziker sendromu, mukokutanöz lentijinler ve melanonişiyle seyreden nadir görülen kalıtsal bir pigment bozuklugudur. Bu sendroma, altta yatan bir malignite ya da sistemik hastalıkla henüz ilişkilendirilmediğinden benign olarak yaklaşılır. Peutz-Jeghers, Cronkhite-Canada sendromu gibi malignite sendromları ve Addison hastalığı, ilaçlar gibi hiperpigmentasyona yol açan durumlar da benzer mukokutanöz bulgularla seyrettiğinden, hastaların bu durumlar dışlanarak değerlendirilmesi önemlidir.

Anahtar kelimeler: Laugier-Hunziker sendromu, mukokutanöz hiperpigmentasyon, melanonişi

\section{Introduction}

Laugier-Hunziker syndrome (LHS) was first described in 1970 in five cases with acquired asymptomatic melanotic hyperpigmented macules of the oral mucosa, lips and fingers and longitudinal melanonychia without any systemic diseases. ${ }^{1}$ To our knowledge approximately 200 cases of LHS were reported to date.

The underlying mechanism leading to the syndrome could not be elicited so far. Moreover, accompanying

Corresponding author: Hande Ermis, Üniversite Mahallesi Farabi Caddesi No:66 KTÜ Deri ve Zührevi Hastalıklar Anabilim Dalı, Ortahisar, Trabzon, Türkiye. Phone: +90 462377 5420, E-mail: handeermis23@gmail.com

Received: 8 June 2021 Accepted: 27 June 2021

Conflicts of Interest: None

Funding: None

How to cite this article: Ermis H. Laugier-Hunziker syndrome: a rare case report and review of the literature. Mucosa 2021:4;50-55

(c) (i) (-) This work is licensed under a Creative Commons Attribution-NonCommercial 4.0 International License. 
systemic disorders and associated malignancy were not established. Since very similar mucocutaneous lesions are also seen in malignancy syndromes, LHS is an exclusion diagnosis. It occurs predominantly in middle-aged individuals with an approximate ratio of female to male of 2:1. Nonetheless, child and adolescent cases and younger individuals were also reported..$^{2-4}$ The inheritance was not proven, however, a familial case of LHS was also reported. ${ }^{5}$ Although an underlying systemic disease could not be shown, accompanying thrombocytopenia, anemia, hypocellular bone marrow, rheumatoid arthritis were reported. ${ }^{6,7}$

\section{Case report}

A 39-year old, smoker, female patient was admitted to our outpatient clinic due to the increasingly spreading dark pigmented asymptomatic lesions in her armpits existing for nine months. The patient did not describe fever, night sweats or weight loss. She denied abdominal pain, melena, hematochezia, fatigue, malaise as well as any malignancy. Her younger sister and maternal aunt were similarly affected. Her medication was limited to escitalopram 10mg/day. Her father died of larynx and colon cancer and her paternal uncle died of stomach cancer.

Physical examination revealed a Fitzpatrick 4 skin with diffuse hyperpigmented macules in axillae (Fig. 1),

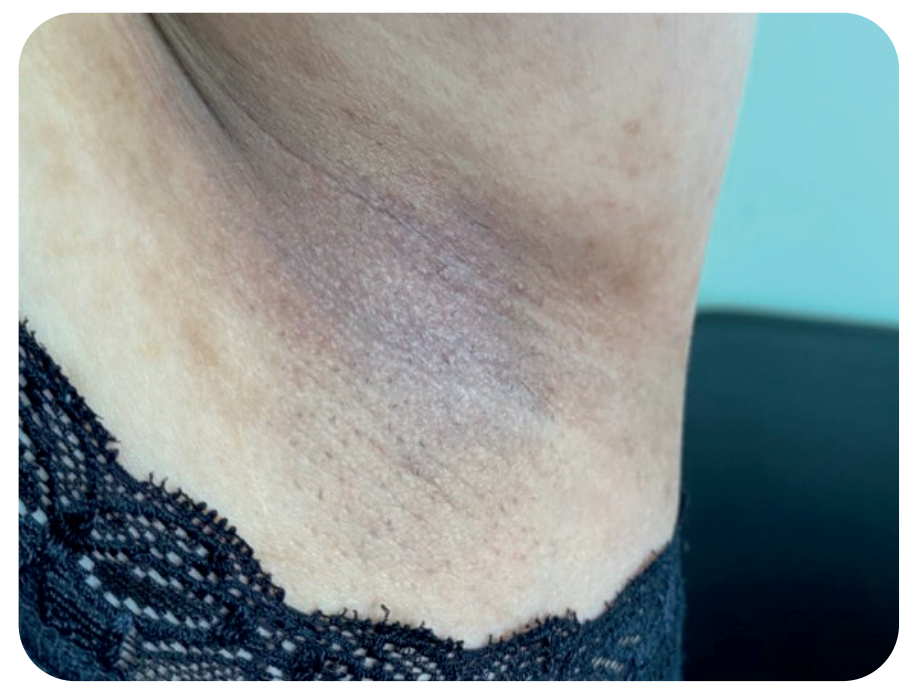

Fig. 1. Diffuse hyperpigmentation of axilla, light-brown discrete macules intermammary skin, labia majora and minora, and discrete hyperpigmented macules in the vestibulum. Bilateral palmar hyperpigmented macules were also detected. (Fig. 2) Moreover, both discrete and slightly coalescing hyperpigmented macules on the inner lips, gingiva (Fig. 3) and hard plate were observed. Regular longitudinal melanonychia of the index and middle finger was seen. Dermatoscopic examination of lentigines on the inner lips disclosed light brown dots and globules in varying sizes, a curvilinear pattern and a reticular pigment network. (Fig. 4) The mucosal lesion revealed a yellowish background. Neither of a ring-like, fish scale-like nor hyphal pattern, which were described mainly in benign mucosal lentiginous lesions, was observed. Subsequently, the patient has undergone a colonoscopy to exclude any malignancy accompanied by mucocutaneous hyperpigmentation disorders, which revealed no abnormal findings. Endoscopy of the upper gastrointestinal tract revealed antral gastritis and bulbitis without any suspicious findings of malignancy. Laboratory tests including complete blood count with renal and liver biochemistry were normal except for a decreased serum hemoglobin and hematocrit level. A peripheric blood smear was performed and revealed hypersegmented neutrophils as wells as hypochromic erythrocytes with anisocytosis. Accordingly, our patient was given iron and B12 replacement therapy.

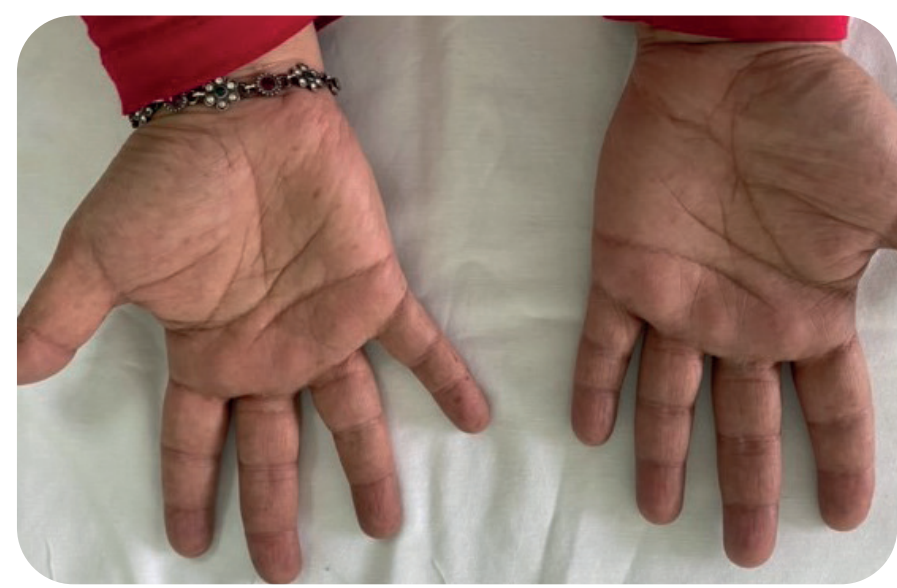

Fig. 2. Discrete macular hyperpigmentation of palms 


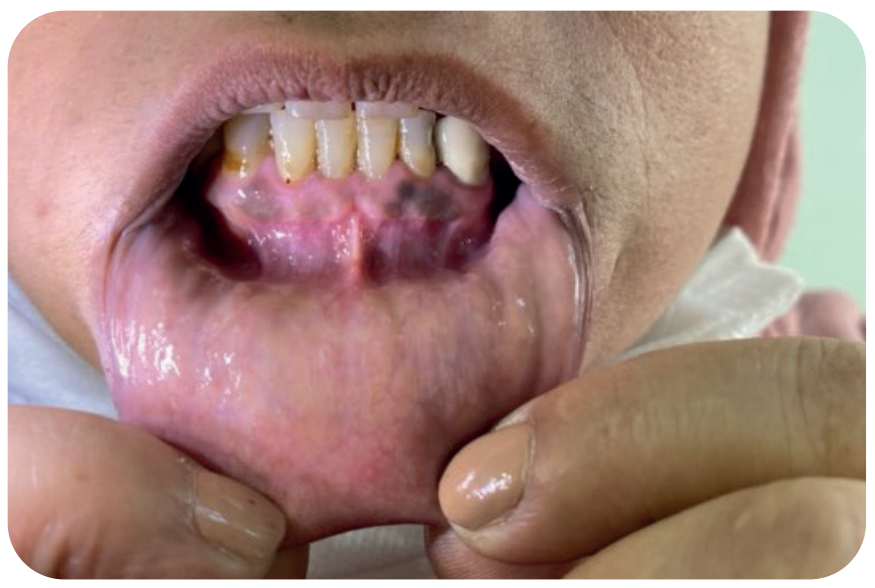

Fig. 3. Hyperpigmented macules on lower gingival mucosa and yellow discoloration of inner lips

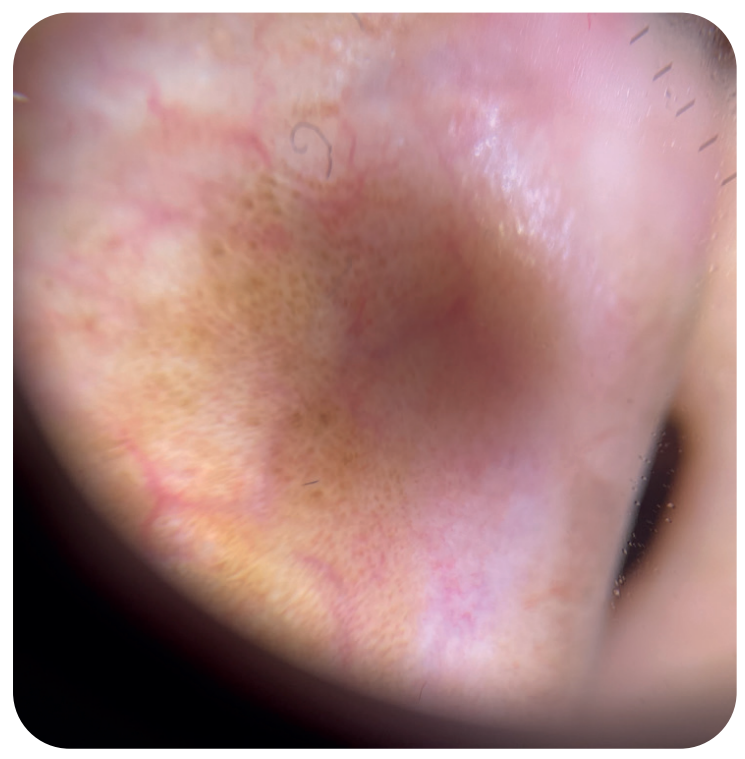

Fig. 4. Light brown dots and globules, a curvilinear pattern and reticular pigment network

A biopsy of a representative lesion on the axillary skin was performed and histopathologic examination displayed hyperkeratosis, a mild spongiosis and increased pigmentation of the basal layer in the epidermis. Pigment incontinence, melanophages and perivascular chronic inflammatory cell infiltration were also reported in the superficial dermis. PAS stain was negative and no spores or hyphae were observed.

A diagnosis of LHS was made according to the distribution of pigmentation, lack of any evidence or suspicion of malignancy and a previous history of malignancy. An informed consent was taken from the patient for publication.

\section{Discussion}

LHS clinically presents mainly with mucosal (oral, labial, gingiva, hard palate, buccal mucosa, conjunctiva, glans penis, vulva, labia majora) and acral lentiginous macules. Less often, macules on the neck and trunk are seen. Longitudinal melanonychia is a typical finding, observed in approximately half of the patients. ${ }^{8}$ Baran described three types of melanonychia in LHS. The first type was described as isolated longitudinal streaks of varying degrees of pigmentation 1 to $2 \mathrm{~mm}$ in width while the second type presents as double longitudinal streaking in one or more fingernails, usually involving the lateral parts of the nail plate 2 to $3 \mathrm{~mm}$ in width. The third variety exerts itself as homogenous staining of the radial or ulnar half of the nail of one or more fingers. ${ }^{9}$

Longitudinal melanonychia is a physiological finding in dark-skinned individuals and can be present in single or multiple pigmented bands in one or more digits. Onychotillomania related traumatic longitudinal melanonychia, drug-induced melanonychia (zidovudine, minocycline, hydroxyurea etc.), lichen planus associated nail hyperpigmentation, exogenous pigmentation (dirt, tobacco, silver nitrate, heavy metals), bacterial infections (P. aeruginosa, Klebsiella and Proteus spp.), onychomycosis, nevus, Bowen's disease and melanoma are the other causes of longitudinal nail hyperpigmentation. ${ }^{8}$ Longitudinal melanonychia in malignancies is typically characterized by grey to black streaks with varying colour and width, and occasionally nail dystrophy, onycholysis and bleeding mass could accompany. Hutchinson's sign (pigmentation of proximal and lateral nail folds adjacent to the nail) is another clinical clue for malignant melanoma. ${ }^{8}$

Dermatoscopically, brown reticular pattern with linear-curvilinear vasculature, multiple brown dots, multiple blue-grey granular patterns and a regular 
brown reticular pattern, homogenous blue area and fish scale-like pattern in mucosal lesions, parallel furrow pattern, fibrillar pattern in the palmoplantar region were reported previously in LHS. ${ }^{8}$

Pathologically, melanin accumulation of the basal layer of the epidermis (sometimes limited to the rete ridges), an increased number of melanophages and pigmentary incontinence in the upper dermis, occasionally increased numbers of non-nested melanocytes in the epithelial basal layer, acanthosis, hyperkeratosis as in our case and spongiosis were described. ${ }^{8}$

Since LHS is an exclusion diagnosis, the overview of diseases with similar presentations should be evaluated elaborately. Syndromic hyperpigmentation disorders are summarized in table 1.

Regarding differential diagnosis, the mucocutaneous lentiginous lesions in Peutz-Jeghers syndrome (PJS) are present at $\% 95$ of cases since birth or develops in infancy, often fade after adolescence. Thereafter buccal lesions usually persist. This autosomal dominant inherited syndrome due to the germline mutation in STK11 gene is associated with gastrointestinal hamartomatous polyps and internal malignancies including colon, breast, pancreas, ovaries etc. In asymptomatic individuals with PJS, a lifetime cancer surveillance including oesophagogastroduodenoscopy and colonoscopy beginning at the age of 8 years, breast imaging and testicular examination are recommended. ${ }^{8}$

Multiple lentigines are also seen in LEOPARD syndrome (lentigines, electrocardiogram abnormalities, ocular hypertelorism, pulmonary stenosis, abnormal genitalia, retardation of growth, deafness). In Carney complexes including LAMB (lentigines, atrial myxoma, mucocutaneous myxoma, blue nevi) and NAME (nevi, atrial myxoma, myxoid neurofibroma, ephelides) syndrome, spotty facial hyperpigmentation is prominent. Oral, genital, conjunctival mucosa may also be affected. ${ }^{8}$

In Addison's disease, the primary adrenal insufficiency, generalized hyperpigmentation prominently in sun- exposed and body sites under chronic pressure of friction were main characteristics. Moreover, the vermilion border of the lips, nails, hair and freckles may darken. Buccal, vaginal and anal mucosal pigmentation also occur. McCune-Albright syndrome is another sporadic disorder due to a somatic mutation of GNAS gene. It presents classically with café-au-lait macules which can be unilateral with midline demarcation or following Blaschko lines. They are mainly located to the neck, sacrum and head. Polyostotic fibrous dysplasia, hyperfunctioning endocrinopathies such as puberty precocious, hyperthyroidism, Cushing syndrome are the main features. ${ }^{8}$

Neurofibromatosis type 1 is an autosomal dominantly inherited disease due to a mutation in the NF1 gene and characterized with café-au-lait macules with smooth borders, in contrast to McCune-Albright syndrome, axillary, and inguinal freckling, multiple neurofibromas, optic glioma, Lisch nodules and skeletal malformations. ${ }^{8}$ Cronkhite-Canada syndrome is a non-hereditary gastrointestinal polyposis syndrome characterized by cutaneous and oral melanotic macules, alopecia, onychodistrophy and seen mainly in men after the $6^{\text {th }}$ decade. ${ }^{8}$

Regarding labial and oral mucosal lesions, amalgam tattoos, smoker's melanosis, drug-induced mucocutaneous pigmentation (minocycline, chloroquine, ketoconazole, clofazimine, zidovudine, cyclophosphamide, doxorubicin, hydroxyurea, amiodarone, oral contraceptives etc), melanocytic nevus and melanoacanthoma, melanoma and physiological ethnic pigmentation are other causes of hyperpigmented lesions. ${ }^{8}$

Since association with any systemic diseases or malignancies could not be established in LHS, it is regarded as a benign condition and no treatment is required. Regarding cosmetic concerns, several case reports of successful therapies with Q-Switched Alexandrite, Er:YAG and Q-switched Nd:YAG laser were published. However, the recurrence of the lesions rises as a challenge to overcome. ${ }^{10}$ 
Table 1. A Summary of syndromic hyperpigmentation disorders

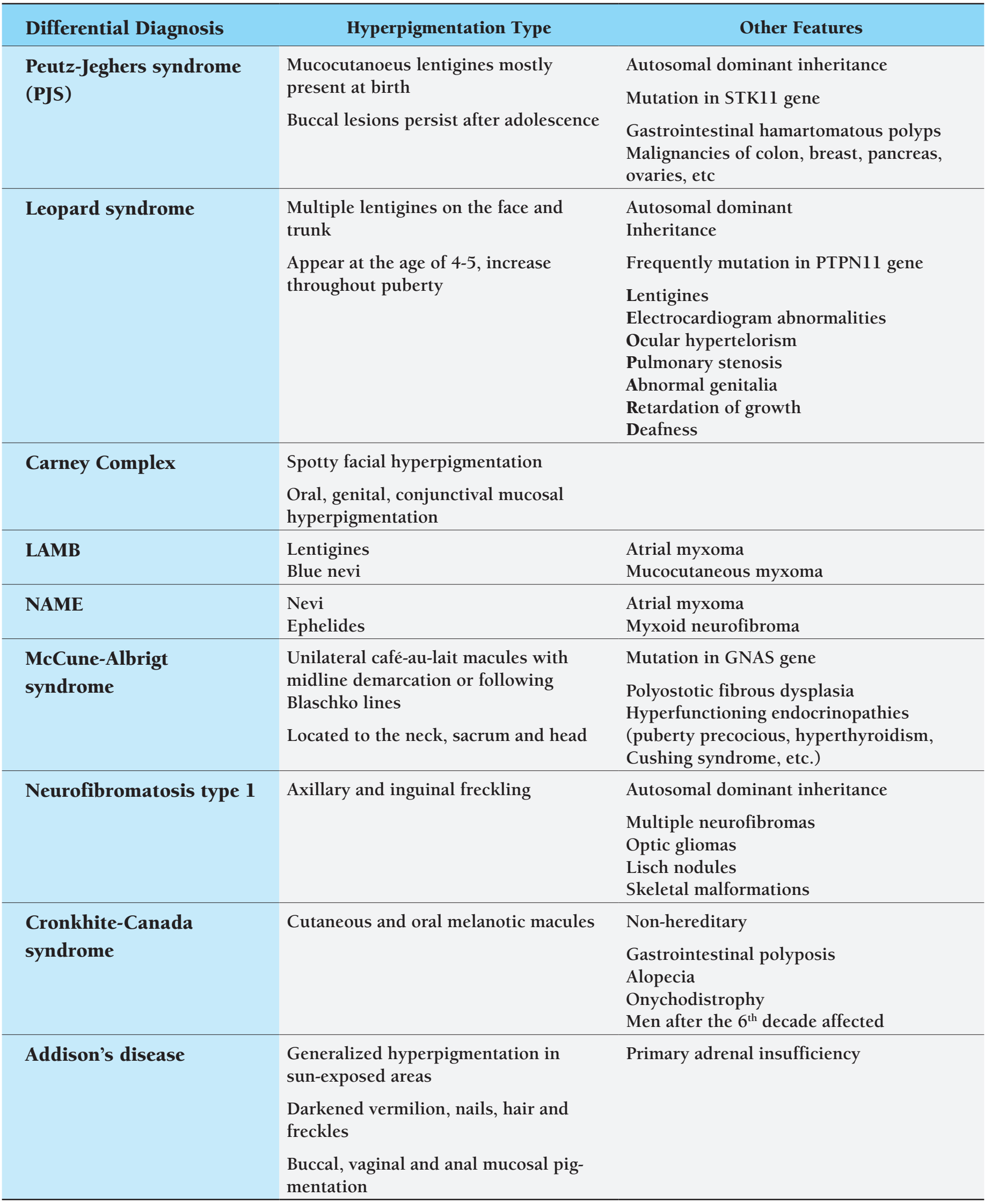


Informed consent: The author certifies that she has obtained all appropriate consent forms from the patient.

Peer-review: Externally peer-reviewed

\section{Authorship contributions:}

Conception and design, or analysis and interpretation of data: HE

Drafting the manuscript or revising the content: HE

Final approval of the version to be published: HE

\section{References}

1. Laugier P, Hunziker N. Essential lenticular melanic pigmentation of the lip and cheek mucosa. Arch Belg Dermatol Syphiligr 1970;26:391-9.

2. Sardana K, Mishra D, Garg V. Laugier Hunziker syndrome. Indian Pediatr 2006;43:998-1000.

3. Panchami Deb Barman AD, Ashim KM, Piyush K. Laugier-Hunziker syndrome revisited. Indian J Dermatol 2016;61:338-9.

4. Kacar N, Yildiz CC, Demirkan N. Dermoscopic features of conjunctival, mucosal, and nail pigmentations in a case of Laugier-Hunziker syndrome. Dermatol Pract Concept 2016;6:23-4.

5. Makhoul EN, Ayoub NM, Helou JF, Abadjian GA. Familial Laugier-Hunziker syndrome. J Am Acad Dermatol 2003;49:143-5.

6. Lee JS, Park KC, Shin JW, Huh CH, Na JI. Two cases of Laugier-Hunziker syndrome with thrombocytopenia. Eur J Dermatol 2018;28:830-1.

7. Enginar A, Karaman NS, Karakas AA. Laugier-Hunziker syndrome in a patient with rheumatoid arthritis. Reumatologia 2019;57:63-5.

8. Duan N, Zhang YH, Wang WM, Wang X. Mystery behind labial and oral melanotic macules: Clinical, dermoscopic and pathological aspects of Laugier-Hunziker syndrome. World J Clin Cases 2018;6:322-34.

9. Baran R. Longitudinal melanotic streaks as a clue to Laugier-Hunziker syndrome. Arch Dermatol 1979;115:1448-9.

10. Nair V. Laugier-Hunziker syndrome: complete clearance of mucosal lentigines with a single session of Q-Switched Nd:YAG laser. J Cosmet Laser Ther 2019;21:343-5. 